
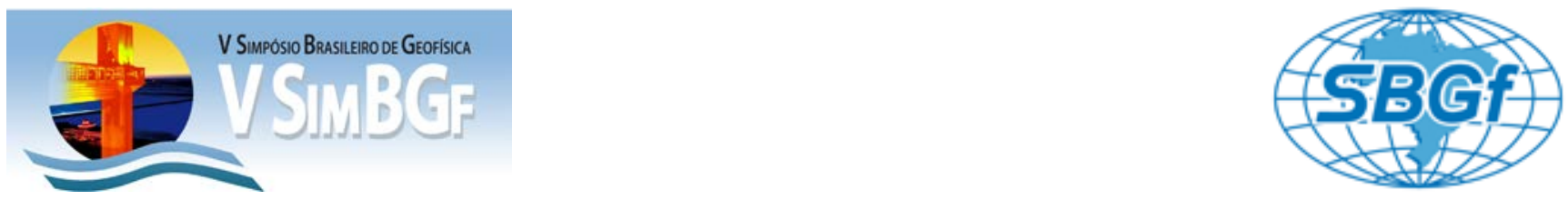

\title{
Contribuição da Geofísica na definição do potencial petrolífero da Bacia do Irecê
} Kátia S. Duarte, ANP-SDT \& Raphael V.A. Vasconcellos, ANP-SDB, André Rugenski, (ANP-SDT-BDEP)

Copyright 2012, SBGf - Sociedade Brasileira de Geofísica

Este texto foi preparado para a apresentação no V Simpósio Brasileiro de Geofísica, Salvador, 27 a 29 de novembro de 2012. Seu conteúdo foi revisado pelo Comitê Técnico do V SimBGf, mas não necessariamente representa a opinião da SBGf ou de seus associados. É proibida a reprodução total ou parcial deste material para propósitos comerciais sem prévia autorização da SBGf.

\section{Resumo}

A Bacia do Irecê, localizada na região centro/norte do Estado da Bahia vem tendo a avaliação do seu potencial petrolífero preterida por conta de algumas características geológicas que a desqualificava entre as prioridades exploratórias, entretanto a ANP, dentro do escopo de seu Plano Plurianual de Geologia e Geofísica - voltado fundamentalmente para as pesquisas em bacias de nova fronteira exploratória - optou por investigar esse potencial, analisando dados geofísicos existentes, para verificar se caberiam investimentos na bacia. O presente trabalho mostra o resultado dessa pesquisa e indica diferentes propostas para futuros estudos na região.

\section{Introdução}

A Bacia do Irecê tem área de aproximadamente 30.300 $\mathrm{km}^{2}$, o que corresponde a quase três vezes a Bacia do Recôncavo, no entanto, apesar dessa expressiva área, ainda não dispõe de dados sísmicos ou um poço perfurado para a pesquisa petrolífera, dessa forma, o conhecimento sobre essa bacia está principalmente relacionado aos estudos geológicos voltados para a pesquisa mineral e de água subterrânea.

As principais dificuldades dessa bacia são principalmente a idade, essencialmente proterozóica, sérias dúvidas quanto a existência de selos eficazes para eventuais reservatórios, dúvidas sobre a existência de rochas geradoras eficazes, além de uma possível baixa espessura indicada pelos dados geofísicos gravimétricos e magnéticos até então disponíveis, entretanto uma análise atualizada dos dados existentes indicaram questões que dependem de respostas antes de se definir o real potencial petrolífero da região. Tais questões se mostraram campo fértil para trabalhos acadêmicos que poderiam preceder investimentos de maior vulto. A indicação das principais questões e algumas propostas de estudos são os principais produtos do presente trabalho.

\section{Histórico Exploratório}

Apesar de não existirem dados sísmicos ou poços perfurados para a pesquisa petrolífera na Bacia do Irecê, os dados geofísicos existentes apontam para um potencial a ser investigado com melhor detalhe. Dados magnetométricos, por exemplo, revelam uma forte anomalia magnética de origem profunda e com foco na porção NW da bacia enquanto dados gravimétricos de satélite, parecem indicar um depocentro na porção NW, (Figuras 1 e 2 respectivamente).

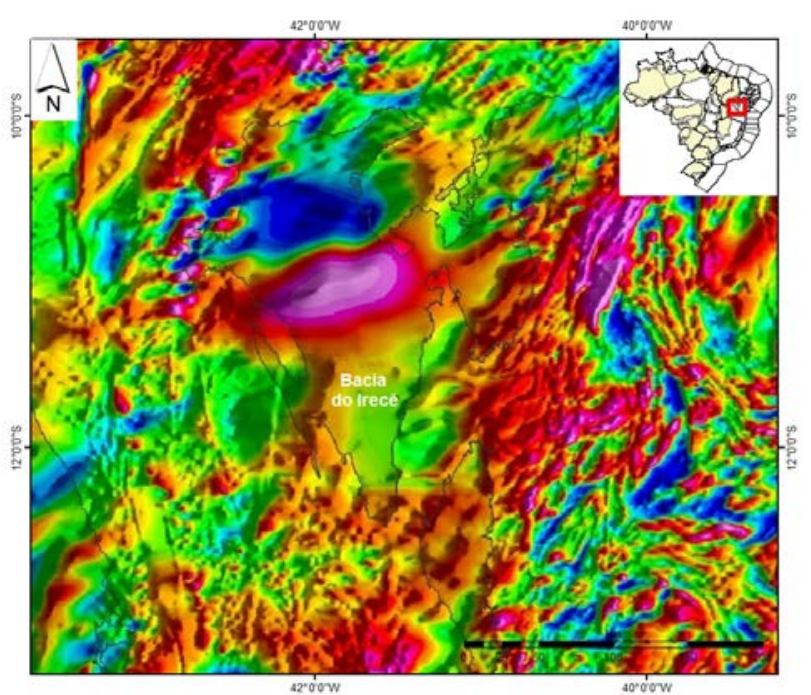

Figura 1 - Mapa Magnetométrico destacando (em linha cinza) a Bacia do Irecê. Observar a forte anomalia magnética na porção norte da bacia.

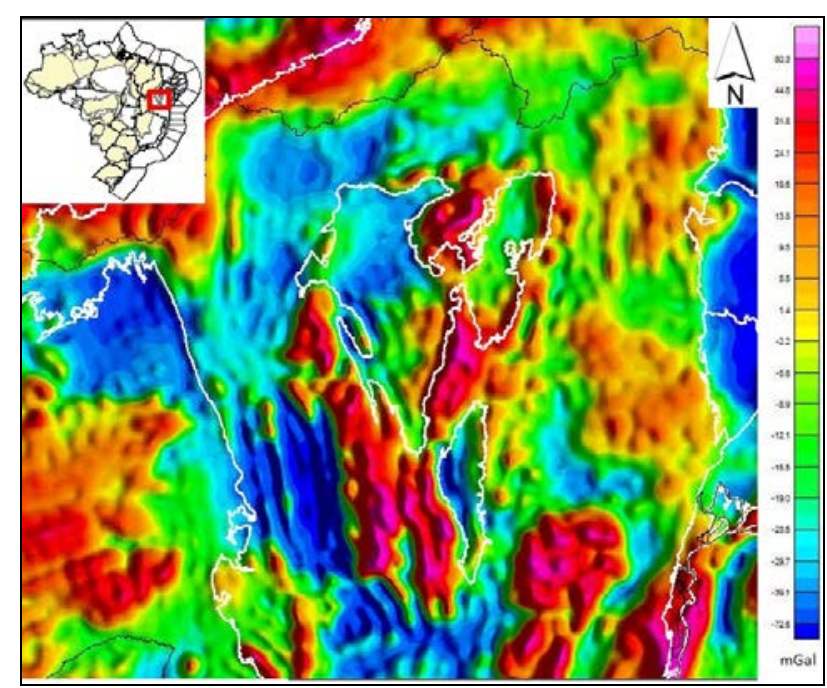

Figura 2 - Mapa gravimétrico de Anomalia Free air do satélite Topex, com a Bacia do Irecê e Lençóis destacadas em branco no centro da imagem.

A Bacia do Irecê corresponde a uma extensa plataforma desenvolvida no cráton de São Francisco durante o Proterozóico. É uma bacia relativamente isolada que é dominantemente preenchida por estratos carbonáticos do Grupo Una, com correlatos na Bacia do São Francisco correspondendo ao Grupo Bambuí. Esta capa de carbonato ocupa uma área de aproximadamente 300.000 $\mathrm{km}^{2}$ (incluindo à Bacia de São Francisco), cobrindo além do próprio cráton, (Almeida, 1977). 
A Bacia do Irecê foi aparentemente formada pelos mesmos movimentos compressionais que formaram a Bacia do São Francisco. Essas bacias mostram sequências estratigráficas similares, contendo uma sequência basal siliciclástica composta principalmente de diamictitos provavelmente de origem glacial (Formações Bebedouro e Macaúba) cobertos por sedimentos lacustres (Torquato e Misi, 1977). Essas unidades são cobertas por sequencias marinhas que possuem no total, centenas de metros de espessura, podendo ser divididas em três pacotes deposicionais na Bacia de Irecê (Misi, 1979, Mascarenhas et al., 1984). Uma sequencia basal é composta por dolomito argiloso (C) e por calcário laminado, calcário dolomítico e siltito dolomito (Unidade B) e dolomito evaporítico B1). Estruturas marinhas sedimentares rasas como lama, estromatólito laminado, e nódulos de calcita/quartzo entre outros pseudomórfos de sulfatos minerais são comuns. A sequência superior (Unidade A) é dominada por intercalações rítmicas de calcário argiláceo acinzentado, folhelho e siltito com lentes de calcarenito localizadas. Essa unidade é exposta principalmente na borda oeste da Bacia de Irecê. Uma sequencia superior (Unidade A1) consiste de grandes blocos de calcário negro, orgânicos com textura oolítica, pisolítica e estratificação cruzada.

Bonfim et al. (1985) propuseram uma outra divisão, nomeando quadro unidades, representando fácies carbonáticas distintas, assim representadas da base para o topo: Unidades Nova América, Gabriel, Jussara e Irecê que Pereira \& Medeiros (2011) esquematizaram com base na variação de fácies dos carbonatos da Formação Salitre.

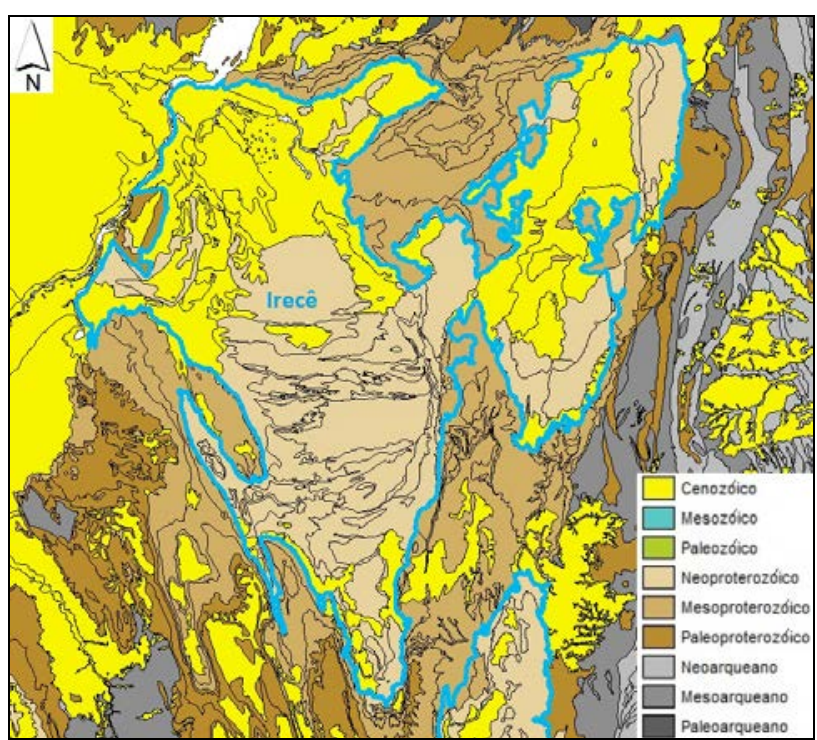

Figura 3 - Mapa Geológico classificado por Eras. Observar que o contorno da bacia (em azul), adotado pela ANP localmente considera unidades Mesoproterozóicas como pertencentes à Bacia do Irecê.

A existência de diferentes divisões estratigráficas indica a necessidade de revisão e integração, inclusive para definir os limites da bacia. O mapeamento da CPRM de 1998, apenas considera os sedimentos das Formações Bebedouro e Salitre, de idade Neoproterozóica, Outros incluem algumas formações Mesoproterozóicas, por exemplo, Morro do Chapéu. As subunidades da Formação Salitre (Irecê, Jussara, Gabriel e Nova América) também não apresentam consenso quanto à nomenclatura e divisão.

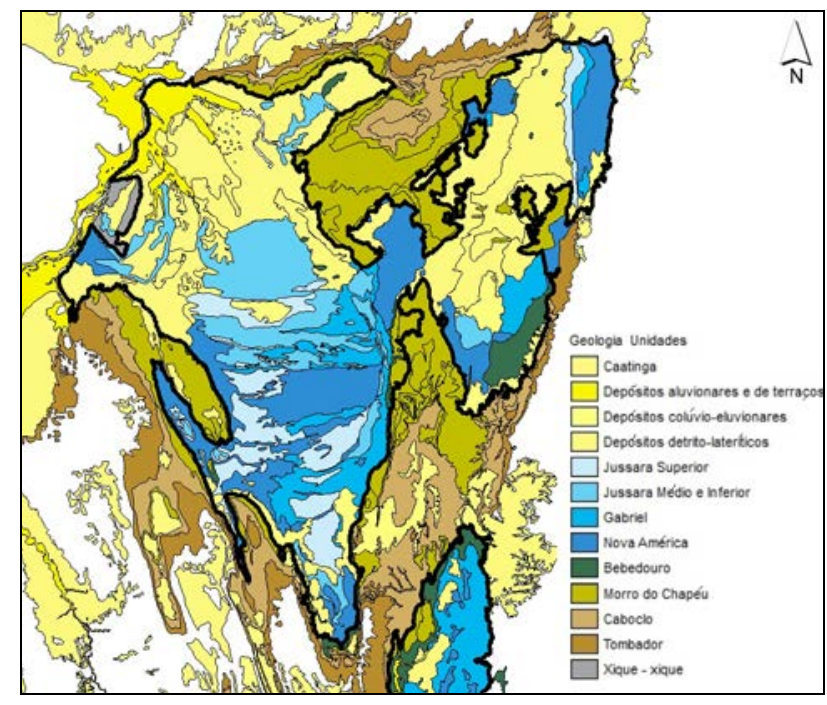

Figura 4 - Mapa Geológico classificado por Unidades. Observar que o contorno da bacia (em preto) adotado pela ANP, localmente considera a Formação Morro do Chapéu como pertencente como pertencente à Bacia do Irecê, sugerindo a necessidade de revisão.

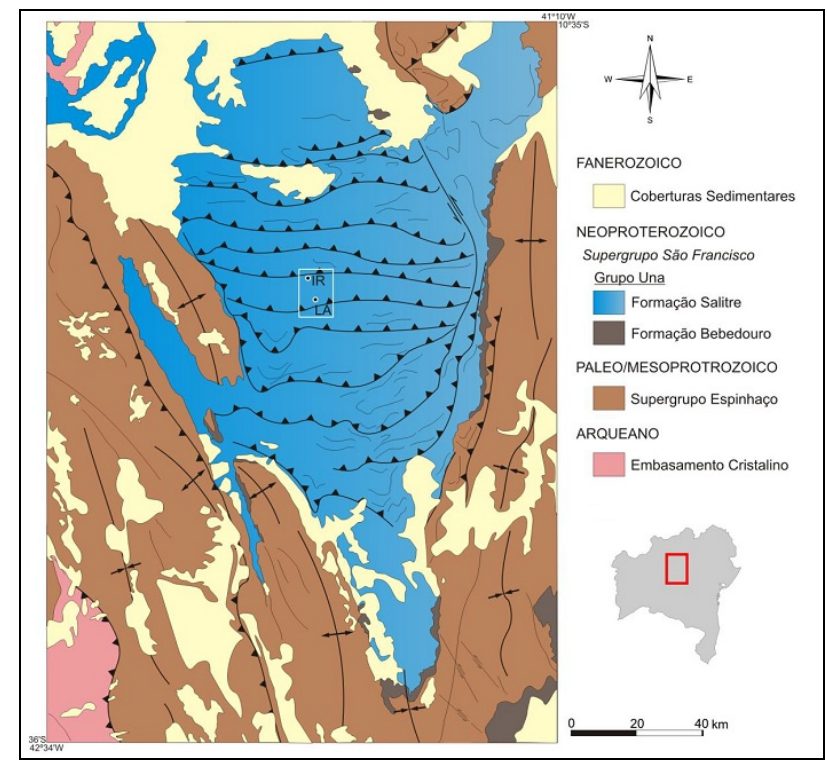

Figura 5 - Mapa geológico sintético da Bacia de Irecê. IR Indica a localidade de Irecê e LA - Lapão. Baseado em Souza et al. (2003) e Kuchenbecker et al. (2011). 


\section{Sistemas e Potencial Petrolífero}

Ainda não existem dados suficientes para sugerir um sistema petrolífero completo para a bacia, porém as similaridades com a Bacia de São Francisco indicam eventual potencial para gás. Todavia, ainda contam desfavoravelmente para a bacia: 1) Indicações de menor espessura sedimentar que a Bacia do São Francisco, possivelmente por configurar uma porção proximal antes dos eventos tectônicos que resultaram na separação das bacias; 2) Carência de análises sistemáticas de COT e pirólise que indiquem a existência e o nível de evolução térmica da matéria orgânica eventualmente preservada nos sedimentos. 3) forte falhamento leste/oeste que poderia atuar como rota de ruga para eventuais hidrocarbonetos formados na bacia (Figura 5).

\section{Discussão e Conclusões}

As unidades da Fm. Salitre (Irecê, Jussara, Gabriel e Nova América) apresentam potencial ainda não totalmente esclarecido, ora para geradoras, ora para reservatórios de hidrocarbonetos. Análises geoquímicas realizadas no trombolito grumoso da Unidade Jussara mostraram COT de $0,21 \%$ e calcilutitos apresentaram COT de 0,16\% segundo Pereira \& Medeiros, 2011. Entretanto, conforme cita Figueiredo, 2011, corpos lenticulares da Unidade B1 (Nova América) de espessuras métricas de calcários pretos se mostram ricos em matéria orgânica. Calcilutitos pretos e calcários oolíticos e psolíticos da Unidade A1 (Irecê-Jussara) também se mostram localmente ricos em matéria orgânica. De qualquer forma, tais rochas ainda carecem de dados de pirólise para atestar a capacidade de geração.

Apesar do forte falhamento mostrado na Figura 5, uma área menos falhada e com cobertura cenozóica aparece na porção NW da bacia, que além de maior depocentro poderia apresentar alguma rocha selante, entretanto, a região carece de dados gravimétricos de melhor resolução do que está apresentado na Figura 2.

Com relação ao meio ambiente, não há restrições que impeçam ou dificultem a exploração da bacia, Entretanto, quanto às questões geológicas, esta bacia ainda carece de estudos que desvendem características relevantes para indústria petrolífera. Algumas sugestões para elevar o conhecimento da mesma são indicadas adiante:

a) Levantamento expedito gravimétrico terrestre, visando confirmar a profundidade do embasamento, em especial na parte NW dessa bacia, com sedimentos cenozóicos cobrindo regiões menos falhadas e assim com possibilidade de espessamento da coluna sedimentar e até mesmo a presença de selo mais eficiente.

b) Amostragem de sedimentos com suspeita de COT elevado visando análises geoquímicas básicas. Essas análises poderiam indicar o nível de evolução térmica da matéria orgânica e a quantidade relativa de hidrocarbonetos ainda presentes nos sedimentos. c) Descrição de amostras obtidas nos poços de perfuração para água ou pesquisa mineral.

d) testar a metodologia de detecção de exsudações com a Banda 9 do sensor ASTER, conduzida com boa correlação na porção sul da Bacia do São Francisco.

\section{Agradecimentos}

Os autores agradecem ao corpo gerencial e técnico da ANP, pelo constante incentivo à pesquisa.

\section{Referências}

Almeida, F.F.M. 1977. O Cráton do São Francisco: Revista Brasileira de Geociências, São Paulo, v. 7, p. 349-364.

Bonfim, L.F.C.; Roch, A.J.D.; Pedreira, A.J.; Morais, J.C., P; Guimares, J.T.; Tesch, N.A. 1985. Projeto Bacia de Irecê. Salvador, CPRM. (Relatório Final).

Figueiredo, A.L.C., 2011, Fácies Carbonéticas e Potencial Reservatório da Formação Salitre Neoproterozóica, na Bacia de Irecê-Bahia, Brasil. Monografia de Graduação, UFBA, 128 p.

Kuchenbecker, M.; Reis, H.L.S., Fragoso, D.G.C., 2011. Caracterização estrutural e considerações sobre a evolução tectônica da Formação Salitre na porção central da Bacia de Irecê, norte do Cráton do São Francisco (BA).

Mascarenhas, J.F.M., Pedreira, A.J., Misi, A., Motta, A.C., Sá, J.H.S. 1984. Província São Francisco, in Almeida, de F.F.M., and Hasui, Y., eds., O Precambriano do Brasil: São Paulo, Ed. Edgard Blücher, p. 46-122.

Misi, A. 1979. O Grupo Bambuí no Estado da Bahia, in Geologia e Recursos Minerais do Estado da Bahia: Textos Básicos: Secretaria das Minas e Energia, Salvador, Bahia, Brasil, v. I, p. 120-154.

Pereira, C. P. \& Medeiros, R. A. 2011. Perfil Longitudinal Esquemático de Variação de Fácies dos Carbonatos da Formação Salitre. In: PEREIRA, C. P. \& REIS, C. C. 2011. Curso de Campo: Carbonatos Microbiais da Bacia do São Francisco. Irecê, p. 15.

Souza, J. D., Kosin M., Melo R.C., Santos R. A., Teixeira L. R., Sampaio A. R., Guimarães J. T., Bento R.V., Borges V. P., Martins A. A. M., Arcanjo J. B., Loureiro H. S. C., ANGELIM L. A. A. 2003. Mapa geológico do Estado da Bahia - Escala 1:1.000.000. Salvador. CPRM, 2003. Versão 1.1. Programas Carta Geológica do Brasil ao Milionésimo e Levantamentos.

Torquato, J.R.F., Misi, A. 1977. Medidas isotópicas de carbono e oxigênio em carbonatos do Grupo Bambuí na região centro-norte do Estado da Bahia: Revista Brasileira de Geociências, São Paulo, v. 7, p. 14-24. 